\title{
Anxiety, Depression and Post-Traumatic Stress Disorder after Earthquake
}

Prakash Thapa, ${ }^{1}$ Lumeshor Acharya,${ }^{2}$ Bhup Dev Bhatta, ${ }^{3}$ Suman Bhatta Paneru, ${ }^{4}$ Jai Bahadur Khattri, Prashant Kumar Chakraborty, ${ }^{1}$ Rajasee Sharma ${ }^{1}$

1Department of Psychiatry, Manipal Teaching Hospital, Fulbari -11, Pokhara, Nepal, ${ }^{2}$ Western Regional Hospital, Ramghat-11, Pokhara, Nepal, ${ }^{3}$ Swastik Referral Laboratory and Research Centre, Ramghat -11, Pokhara, Nepal, ${ }^{4}$ BP Koirala Institute of Health Sciences, Dharan, Nepal.

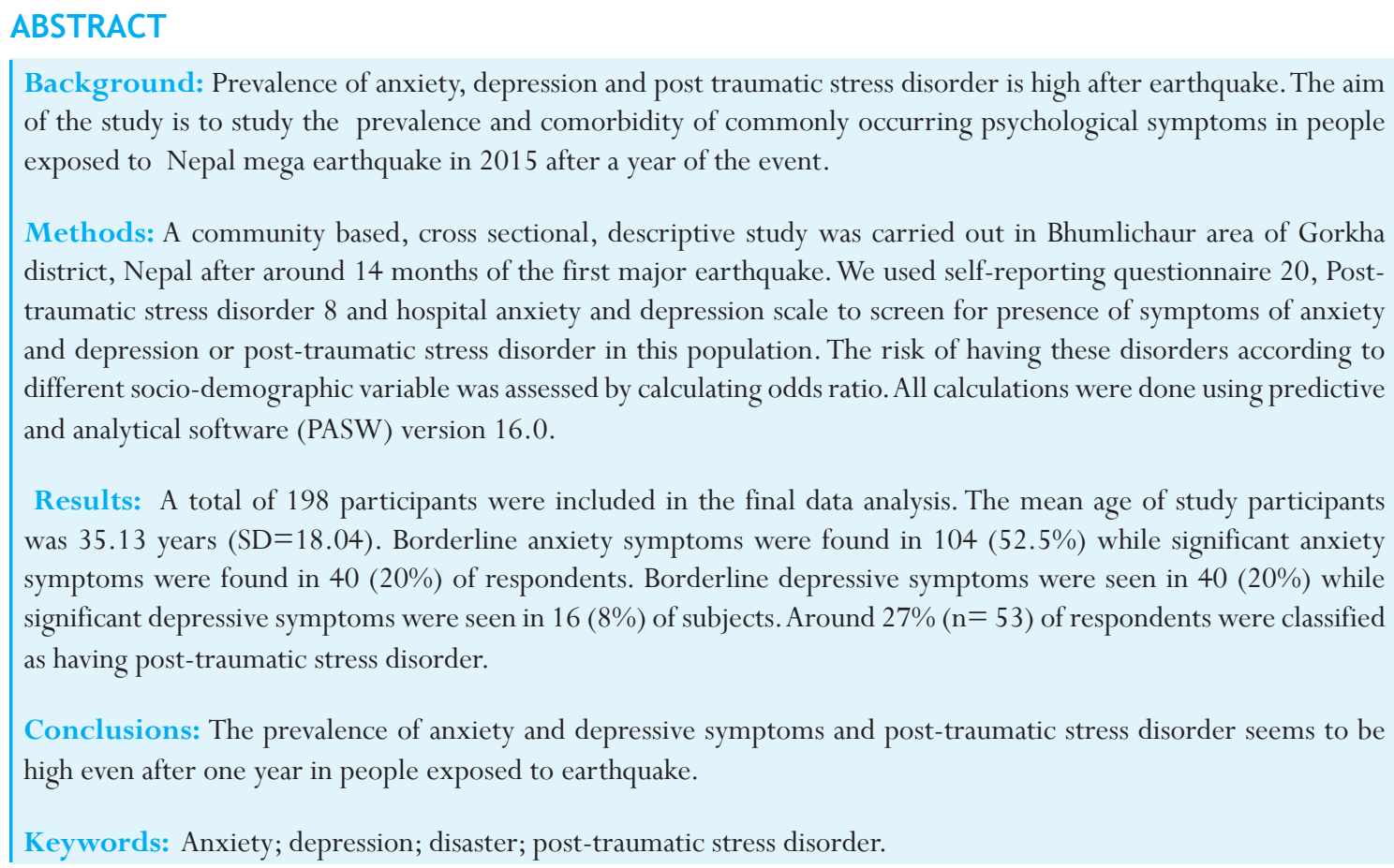

\section{INTRODUCTION}

A major earthquake of magnitude $7.8 \mathrm{M}_{\mathrm{w}}$ hit Nepal on 25 April 2015. It killed 8669 people and injured16,808 people. Hundreds of thousands of people were made homeless as 288,793 buildings were damaged and 254,114 buildings were partially damaged. It was followed by 459 aftershocks of $\geq 4$ magnitude until $28^{\text {th }}$ May 2016. ${ }^{1}$ Such disasters may increase psychological morbidity by more than $17 \% .^{2}$ Some studies have suggested that the major post disaster psychiatric presentation is a conglomeration of post-traumatic stress disorder (PTSD), depression and anxiety symptoms. ${ }^{3}$ Such psychiatric symptoms may even last for years or even decades. ${ }^{4}$ Some studies suggest that psychological symptoms may be more prolonged in adoloscents. ${ }^{5}$
Two previous studies from Nepal have assessed psychiatric comorbidity in earthquake victims with contradictory findings. A study conducted in three earthquake affected districts Kathmandu, Gorkha and Sindhupalchowk found high levels of depression, anxiety but low levels of PTSD. ${ }^{6}$ Another study has reported prevalence of $27.1 \%$ of PTSD in adoloscents. ${ }^{7}$

We carried out this study to find out the prevalence and comorbidity of the most frequently seen psychological symptoms i.e. PTSD, depression and anxiety in people exposed to this mega earthquake after a year of exposure.

\section{METHODS}

A community based, cross sectional, descriptive study was carried out in Bhumlichaur area of Gorkha district, 
Nepal. Data was collected from $22^{\text {nd }}-24^{\text {th }}$ june 2016 i.e. nearly about 14 months after the disaster after obtaining ethical clearance from institutional review committee of Manipal teaching hospital, Pokhara, Nepal. Data was collected after getting informed consent from the participants by second and third authors. A predesigned proforma was used to collect information regarding relevant sociodemographic details. Other tools used for data collection were:SRQ20, PTSD8 and HADS.

The Self Reporting Questionnaire (SRQ) is a scale designed to screen for psychiatric disturbances. It contains 20 items which question the respondent about symptoms likely to be present in neurotic disorders. Each question is scored either 0 (for absence of symptoms in last one month) or 1 (for presence of symptoms in last one month). The maximum score is $\mathbf{2 0}$. Its psychometric properties have been demonstrated to be good. ${ }^{8} \mathrm{~A}$ cutoff of $\geq 7$ was chosen to indicate "caseness" in current study.

PTSD8 is a brief screening inventory which can be used to screen for PTSD. It contains eight items. Each item is rated on a four point likert scale; $1=$ "not at all", $2=$ "rarely", 3= "sometimes", 4= "often". These items are divided into three symptom clusters with question 1-4 being intrusion items, questions 5 and 6 being avoidance items and questions 7 and 8 being hypervigilance item. The criterion for a symptom cluster is met if any of the items in that cluster is scored $\geq 3$. To meet the diagnostic criteria for PTSD criteria for all three symptom clusters have to be met along with following criteria: The event has to involve actual or threatened death, serious injury, or a threat to the physical integrity of self or other and the experience of intense fear, helplessness or horror. The symptoms have to be present for at least one month after the trauma and cause clinically significant distress or impairment in social, occupational, or other important areas of functioning. The psychometric properties of this scale have been demonstrated to be adequate. ${ }^{9}$

Hospital anxiety and depression scale (HADS) is a short screening instrument to screen for depression and anxiety which has been used extensively in community surveys. It consists of 14 items. Half of these items form depression subscale while the other half forms anxiety subscale. Each of these items is rated on a four point Likert scale ranging from 0 to 3 . A summed score of $0-7$ is considered normal, $8-10$ is considered borderline and $\geq$ 11 signifies caseness. Recently HADS has been translated in Nepalese language. Its psychometric properties have been demonstrated to be acceptable. ${ }^{10}$ In this study we used the Nepalese version of HADS.
Data were analyzed using predictive and analytical software (PASW) version 16.0. Continuous data are presented as mean and standard deviation; categorical data are presented as frequency and percentages. Odds ratio (OR) with their 95\% confidence interval $(\mathrm{Cl})$ were calculated to assess the risk of being classified as having PTSD, depression or anxiety according to different categories of relevant sociodemographic variables.

\section{RESULTS}

Data was collected from 206 participants but data from eight participants were incomplete so their data was not included in the final data analysis. Hence a total of 198 participants were included in the final data analysis. The mean age of study participants was 35.13 years $(S D=18.04)$ with youngest participant being 18 years of age and the eldest participant being 88 years of age. Most of the participants were illiterate with the modal number of education obtained being zero years. (Table 1)

\begin{tabular}{|c|c|c|}
\hline \multicolumn{2}{|c|}{ Variables } & $N(\%)$ \\
\hline \multirow[t]{4}{*}{ Age groups (years) } & $18-30$ & $101(51 \%)$ \\
\hline & $31-50$ & 61 (30.8\%) \\
\hline & $51-65$ & $23(11.6 \%)$ \\
\hline & $>65$ & $13(6.6 \%)$ \\
\hline \multirow[t]{2}{*}{ Sex } & female & $124(62.6 \%)$ \\
\hline & male & 74 (37.4\%) \\
\hline \multirow[t]{2}{*}{ Marital status } & unmarried & $56(29.3 \%)$ \\
\hline & married & $140(70.7 \%)$ \\
\hline \multirow[t]{5}{*}{ Occupation } & housewife & $28(14.1 \%)$ \\
\hline & farmer & 96 (48.5\%) \\
\hline & student & 50 (25.3\%) \\
\hline & Business & $1(0.5 \%)$ \\
\hline & others & $23(11.6 \%)$ \\
\hline
\end{tabular}

Among the study participants 17 (8.6\%) had past history of receiving treatment for psychiatric disorder. Five (2.5\%) of patients had experienced another traumatic experience in the last 3 years. Around $41 \%$ of the participants of the current study fulfilled the criteria for psychiatric "caseness" as indicated by a score of $\geq 7$ in SRQ 20.

The distribution of patients classified into different categories by the scales used in this study is shown in table 2 . 
Anxiety, Depression and Post-Traumatic Stress Disorder after Earthquake

Table 2. Shows distribution of patients in different diagnostic categories.

\begin{tabular}{|c|c|c|}
\hline Scale & Categories & $N(\%)$ \\
\hline \multirow[t]{2}{*}{ SRQ 20} & Negative & 117 (59.1\%) \\
\hline & positive & $81(40.9 \%)$ \\
\hline \multirow[t]{2}{*}{ PTSD 8} & No PTSD & $145(73.2 \%)$ \\
\hline & PTSD & $53(26.8 \%)$ \\
\hline \multirow[t]{3}{*}{ HADS A subscale } & No anxiety & 94 (47.5\%) \\
\hline & Borderline anxiety & $64(32.3 \%)$ \\
\hline & Anxiety & $40(20.2 \%)$ \\
\hline \multirow[t]{3}{*}{ HADS D subscale } & No depression & $142(71.7 \%)$ \\
\hline & $\begin{array}{l}\text { Borderline } \\
\text { depression }\end{array}$ & $40(20.2 \%)$ \\
\hline & Depression & $16(8.1 \%)$ \\
\hline
\end{tabular}

Among the study participants $29 / 198$ (14.6\%) of patients had more than one diagnoses. The commonest pattern of comorbidity was presence of both PTSD and anxiety in the same patient. This pattern was observed in $7.6 \%$ of the patients. Presence of all three diagnoses in the same patient was seen in $1.5 \%$ of the patients.(Table 3 )

\section{Table 3. Shows pattern of comorbid diagnosis.}

\begin{tabular}{ll} 
Comorbid diagnoses & N (\%) \\
\hline PTSD + probable depression & $5(2.5 \%)$ \\
\hline PTSD + probable anxiety & $15(7.6 \%)$ \\
\hline Probable Anxiety + probable depression & $6(3 \%)$ \\
\hline PTSD + probable Anxiety + depression & $3(1.5 \%)$ \\
\hline
\end{tabular}

The relationship of different sociodemographic variables with the risk of being classified as having PTSD, depression or anxiety was assessed by calculating OR with $95 \% \mathrm{Cl}$. Statistically significant increase in risk of having PTSD was seen in people $<30$ years ofage and unmarried people. Whereas the risk of anxiety and depression was statistically significantly more in females compared to males. (Table 4)

\begin{tabular}{|c|c|c|c|c|c|c|c|c|c|c|}
\hline \multicolumn{2}{|c|}{$\begin{array}{l}\text { Sociodemographic } \\
\text { variables }\end{array}$} & \multicolumn{2}{|c|}{ PTSD 8} & \multirow{2}{*}{$\begin{array}{r}\text { OR }(95 \% \mathrm{Cl}) \\
\text { positive }\end{array}$} & \multicolumn{2}{|c|}{ HADS A } & \multirow{2}{*}{$\begin{array}{r}\text { OR }(95 \% \mathrm{Cl}) \\
\text { positive }\end{array}$} & \multicolumn{2}{|c|}{ HADS D } & \multirow{2}{*}{$\begin{array}{r}\text { OR }(95 \% \\
\mathrm{Cl})\end{array}$} \\
\hline positive & & negative & & & negative & & & negative & & \\
\hline \multirow[t]{2}{*}{$\begin{array}{l}\text { Age } \\
\text { (years) }\end{array}$} & $<30$ & 36 & 65 & \multirow{2}{*}{$\begin{array}{r}2.606 \\
(1.342 ; \\
5.058)\end{array}$} & 17 & 84 & \multirow{2}{*}{$\begin{array}{r}0.651 \\
(0.323 ; 1.311)\end{array}$} & 8 & 93 & 0.975 \\
\hline & $\geq 30$ & 17 & 80 & & 23 & 74 & & 8 & 89 & $\begin{array}{r}(0.344 ; \\
2.659)\end{array}$ \\
\hline \multirow[t]{2}{*}{ Sex } & Female & 38 & 86 & \multirow{2}{*}{$\begin{array}{r}1.738 \\
(0.877 \\
3.442)\end{array}$} & 33 & 91 & 3.471 & 15 & 109 & 10.045 \\
\hline & Male & 15 & 59 & & 7 & 67 & $\begin{array}{l}\text { (1.447; } \\
8.322)\end{array}$ & 1 & 73 & $\begin{array}{l}\text { (1.298; } \\
77.713)\end{array}$ \\
\hline \multirow{2}{*}{$\begin{array}{l}\text { Marital } \\
\text { status }\end{array}$} & Unmarried & 23 & 35 & \multirow[b]{2}{*}{$\begin{array}{r}(1.241 ; \\
4.676)\end{array}$} & 11 & 47 & \multirow{2}{*}{$\begin{array}{r}0.895 \\
(0.413 ; 1.941)\end{array}$} & 1 & 57 & 0.1462 \\
\hline & married & 30 & 110 & & 29 & 111 & & 15 & 125 & $\begin{array}{r}(0.018 ; \\
1.133)\end{array}$ \\
\hline \multirow{2}{*}{$\begin{array}{l}\text { Past } \\
\text { history }\end{array}$} & Yes & 5 & 12 & \multirow{2}{*}{$\begin{array}{r}1.154 \\
(0.386 \\
3.448)\end{array}$} & 1 & 16 & \multirow{2}{*}{$\begin{array}{r}0.228 \\
(0.293 ; 1.769)\end{array}$} & 1 & 16 & 0.692 \\
\hline & No & 48 & 133 & & 39 & 142 & & 15 & 166 & $\begin{array}{r}(0.086 ; \\
5.582)\end{array}$ \\
\hline
\end{tabular}

\section{DISCUSSION}

The major finding of this study is the high prevalence of psychiatric disorders in people exposed to severe trauma after one year of exposure. In this study "caseness" was observed in $81 / 198(41 \%)$ of respondents using SRQ20 at a cut off of $\geq 7$. Similar rate of caseness has been previously reported. ${ }^{3}$

Current study found borderline anxiety symptoms in $104 / 198(52.5 \%)$ of respondents while probable anxiety disorder was found in $40 / 198$ (20\%) of respondents. Elevated estimates of anxiety disorder in people exposed to major disaster have been reported previously. ${ }^{3}$ Current study has also found presence of borderline anxiety symptoms in a high number of disaster exposed population. It is currently not known how the presence of subsyndromal anxiety symptoms affects the functional outcome, quality of life and overall prognosis of people exposed to major disaster as the existing literature in this area is scarce. Further studies in this area are warranted.

Around $27 \%(n=53 / 198)$ of respondents in the current study were classified as having PTSD by PTSD 8 . There is a wide variation in reported prevalence of PTSD following 
exposure to major disaster. Rates as low as $2.5 \%$ and higher than $90 \%$ have been reported previously. ${ }^{11,12}$ This may be because of the multifactorial nature of the etiology of PTSD with age, gender, education, marital status, extent of exposure, past history of mental illness, individuals' resilience and available social support all being the mediating factor in occurrence of PTSD as well as methodological differences in the studies being conducted. Most studies have reported prevalence of PTSD to be in the lower half this range. ${ }^{13,14}$

Some long-term studies of prevalence of PTSD in disaster exposed victims indicate that the prevalence of PTSD decreases with time. ${ }^{15}$ However some studies show that there might in fact be a rise in prevalence of PTSD in a few years following exposure to disaster. ${ }^{16,17}$ This may be because of emergence of late onset PTSD. It is therefore important to provide appropriate support to victims of major disaster in the long term.

Current study has found a relatively low prevalence of probable depression i.e. $8 \%(16 / 198)$, though borderline depressive symptoms were present in $20 \%(40 / 198)$ patients. This prevalence falls in the range $(5.8 \%-54 \%)$ reported by a previous meta-analysis. ${ }^{18}$ One previous study has reported spontaneous resolution of depressive symptoms in some patients exposed to trauma with time. The improvement of depressive symptoms was in part ascribed to subsidence of grief and rising of hope for social and economic recovery. ${ }^{19}$ Similar mechanism may explain this relatively low prevalence of significant depressive symptoms after a year of event.

In the overall sample $29 / 198(14.6 \%)$ of patients had more than one diagnosis with $3 / 198(1.5 \%)$ having three diagnoses and 26/198 (13\%) having any two diagnoses. Previous studies also have reported very similar findings on comorbidity. ${ }^{3}$ A meta-analysis published in 2013 has estimated the rate of PTSD- major depressive disorder comorbidity to be around $50 \%(95 \% \mathrm{Cl}=48-56 \%) .{ }^{20}$ In our study however only $15 \%(8 / 53)$ of patients had comorbid probable depression and PTSD. This lower rate of comorbidity could be due to finding of relatively lower prevalence of depression in our study sample. It is important to note however that co-occurring depression and PTSD is associated with greater degree of distress, impairment and health care utilization. ${ }^{21}$ The rates of comorbidity between probable anxiety disorder and PTSD was higher in our sample 18/53 (33.9\%).

The odds of having probable anxiety $(\mathrm{OR}=3.47195 \% \mathrm{Cl}$ $=1.447 ; 8.322)$ and probable depression $(\mathrm{OR}=10.045$ $95 \% \mathrm{Cl}=1.298 ; 77.713$ ) were more in females compared to males. The risk of having PTSD was statistically significantly more in people < 30 years of age compared to older people $(\mathrm{OR}=2.60695 \% \mathrm{Cl}=1.342 ; 5.058)$ and in unmarried people $(\mathrm{OR}=2.40995 \% \mathrm{Cl}=1.241 ; 44.676)$ compared to married people. Higher prevalence of PTSD in younger people and unmarried or previously married people had been previously reported. ${ }^{22}$

The finding of current study needs to be interpreted in the background of its limitations. The first limitation is its relatively small size. Another important limitation of the study is that the tool used to assess PTSD i.e, PTSD 8 generates DSM IV diagnosis while the criteria have slightly been changed in DSM V. Some scales e.g, PTSD checklist for DSM V (PCL 5) which generate DSM $\checkmark$ criteria are available but they have not been as well validated as the older ones and only preliminary reports of psychometric properties are available. ${ }^{23}$ Further, more studies suggest that changes in diagnostic criteria have made minimal impact on prevalence of PTSD with DSM $\mathrm{V}$ prevalence being only slightly lower (typically around 1\%) than DSM IV prevalence. ${ }^{24}$ Finally, another important limitation to be considered is the use of HADS to assess presence of anxiety and depression. Since HADS is a screening tool, it can only indicate probable presence of anxiety and depression and definite diagnosis of either disorder cannot be made using this tool. Further studies in this area may obviate this shortcoming by performing face to face interview with patients or by using diagnostic tools.

\section{CONCLUSIONS}

The prevalence of anxiety, depression and post traumatic stress disorder are increased even after one year of earthquake in affected district of Gorkha.

\section{REFERENCES}

1. Seismonepal.gov [internet]. Nepal: National seismological

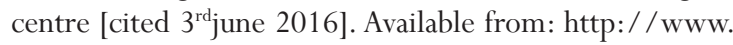
seismonepal.gov.np/index.php?linkId=146

2. Rubonis AV, Bickman L. Psychological impairment in the wake of disaster: The disaster-psychopathology relationship. Psychol Bull. 1991;109(3):384.[PubMed]

3. Kar N, Bastia BK. Post-traumatic stress disorder, depression and generalised anxiety disorder in adolescents after a natural disaster: a study of comorbidity. Clin Pract Epidemiol Ment Health. 2006;2(1):17..[PubMed]

4. Green BL, Lindy JD, Grace MC, Gleser GC, Leonard AC, Korol M, Winget C. Buffalo Creek survivors in the second decade: Stability of stress symptoms. American journal of orthopsychiatry. $1990 \mathrm{Jan} ; 60(1): 43$..[Full Text] 
5. Yule W, Bolton D, Udwin O, Boyle S, O’Ryan D, Nurrish J. The long-term psychological effects of a disaster experienced in adolescence: I: The incidence and course of PTSD. J Child Psychol Psychiat. 2000;41(4):503-11.. [Wiley Online library]

6. Luitel NP, Kane J, Jordans M, Kohrt B, Weissbecker I, Tol W. Mental health and psychosocial needs after the earthquakes: In-depth needs and resource assessment. In: Karki KB, Dhimal M, Aryal KK, Joshi A, Pandey AR, editors. abstract book of second national summit of health and population scientist in Nepal; 2016 april 11 12; Kathmandu, Nepal: Nepal Health Research Council; 2016. P. 15-16.

7. Mishra D, Giri D. Prevalence of Posttraumatic stress disorder(PTSD)and associated factors among adolescents after 2072 earthquake. In: Karki KB, Dhimal M, Aryal KK, Joshi A, Pandey AR, editors. abstract book of second national summit of health and population scientist in Nepal; 2016 april 11-12; Kathmandu, Nepal: Nepal Health Research Council; 2016. P. 55-56.

8. Beusenberg M, Orley JH, World Health Organization. A User's guide to the self reporting questionnaire (SRQ [Full Text]

9. Hansen M, Andersen TE, Armour C, Elklit A, Palic S, Mackrill T. PTSD-8: a short PTSD inventory. Clin Pract Epidemiol Ment Health. 2010;6:101.[PubMed]

10. Risal A, Manandhar K, Linde M, Koju R, Steiner TJ, Holen A. Reliability and validity of a Nepali-language version of the Hospital Anxiety and Depression Scale (HADS). Kathmandu Univ Med J. 2017;13(2):115-24.[PubMed]

11. Amstadter AB, Acierno R, Richardson LK, Kilpatrick DG, Gros DF, et al. Posttyphoon prevalence of posttraumatic stress disorder, major depressive disorder, panic disorder, and generalized anxiety disorder in a Vietnamese sample. J Trauma Stress.2009;22: 180-188.[PubMed]

12. Niaz U, Hassan S, Hassan M. Post-traumatic stress disorder (PTSD), depression, fear and avoidance in destitute women, earthquake survivors of NWFP, Pakistan. Journal of Pakistan Psychiatric Society. 2007;4(1):44.[Full Text]

13. Liu A, Tan H, Zhou J, Li S, Yang T, Wang J, Liu J, Tang X, Sun Z, Wen SW. An epidemiologic study of posttraumatic stress disorder in flood victims in Hunan China. Can J Psuchiatry. 2006;51(6):350-4.[PubMed]

14. Parslow RA, Jorm AF, Christensen H. Associations of pretrauma attributes and trauma exposure with screening positive for PTSD: Analysis of a community-based study of 2085 young adults. Psychol Med. 2006;36(3):387-95. [PubMed]
15. Pietrzak RH, Tracy M, Galea S, Kilpatrick DG, Ruggiero KJ, Hamblen JL, Southwick SM, Norris FH. Resilience in the face of disaster: prevalence and longitudinal course of mental disorders following hurricane Ike. PLoS One. 2012;7(6):e38964.[Full Text]

16. Berninger A, Webber MP, Cohen HW, Gustave J, Lee R, Niles JK, Chiu S, Zeig-Owens R, Soo J, Kelly K, Prezant DJ. Trends of elevated PTSD risk in firefighters exposed to the World Trade Center disaster: 2001-2005. Public Health Rep. 2010;125(4):556-66.[PubMed]

17. Wang X, Gao L, Shinfuku N, Zhang H, Zhao C, Shen Y. Longitudinal study of earthquake-related PTSD in a randomly selected community sample in north China. Am J Psychiatry. 2000;157(8):1260-6.[PubMed]

18. Tang B, Liu X, Liu Y, Xue C, Zhang L. A meta-analysis of risk factors for depression in adults and children after natural disasters. BMC Public Health. 2014;14(1):623. [Full Text]

19. Goenjian AK, Steinberg AM, Najarian LM, Fairbanks LA, Tashjian M, Pynoos RS. Prospective study of posttraumatic stress, anxiety, and depressive reactions after earthquake and political violence. Am J Psychiatry. 2000;157(6):911895.[PubMed]

20. Rytwinski NK, Scur MD, Feeny NC, Youngstrom EA. The co-occurrence of major depressive disorder among individuals with posttraumatic stress disorder: a metaanalysis. J Trauma Stress. 2013;26(3):299-309.[PubMed]

21. Chan D, Cheadle AD, Reiber G, Unützer J, Chaney EF. Health care utilization and its costs for depressed veterans with and without comorbid PTSD symptoms. Psychiatr Serv. 2009;60(12):1612-7.[PubMed]

22. Creamer M, Burgess P, McFarlane AC. Post-traumatic stress disorder: findings from the Australian National Survey of Mental Health and Well-being. Psychol Med. 2001;31(7):1237-47.[PubMed]

23. Sveen J, Bondjers K, Willebrand M. Psychometric properties of the PTSD Checklist for DSM-5: a pilot study. Eur J Psychotraumatol. 2016;7(1):30165.[PubMed]

24. Kilpatrick DG, Resnick HS, Milanak ME, Miller MW, Keyes KM, Friedman MJ. National estimates of exposure to traumatic events and PTSD prevalence using DSM-IV and DSM- 5 criteria. J Trauma Stress. 2013;26(5):537-47. [Full Text] 